The version of Record of this manuscript has been published and is available in Women: A Cultural Review, 29 Mar 2018, https://doi.org/10.1080/09574042.2018.1425536

\title{
Mothering Across Languages and Cultures in Ying Chen's Letters to her Children
}

\section{Eglè Kačkutė}

Department of Romance Philology, Vilnius University, Vilnius, Lithuania

Address for correspondence:

Dr Eglè Kačkutė

Universiteto 5, LT-01513 Vilnius

Email: ekackute@gmail.com

Dr. Eglè Kačkute is a lecturer at Vilnius University and a Postdoctoral Fellow at Maynooth University. She received her PhD from Vilnius University in 2011. Her dissertation, which focussed on identity in contemporary British and French women's writing, was a finalist in the Best $\mathrm{PhD}$ Awards Lithuania in 2011. It was published in Lithuanian as Svetimos ir Savos (Strange and Familiar Selves) in 2012. Her current research examines what it means to mother in a culturally and linguistically foreign environment through literary narratives of mothering in migration in transnational women's writing. 


\title{
Mothering Across Languages and Cultures in
}

\section{Ying Chen's Letters to her Children}

\begin{abstract}
Due to intensifying global mobility, increasing numbers of women find themselves mothering in countries that are linguistically and culturally foreign to them, dealing with issues related to multilingualism, shifting identities, and to belonging. The essays La lenteur des montagnes (The Slowness of the Mountains, 2014) and 'Lettre d'Umbertide' (Letter from Umbertide, 2004) by the Chinese born Canadian author Ying Chen provides a brilliant example. Using recent research on contemporary Asian women's writing in diaspora, notions of écriture migrante as well as nomadic consciousness as a framework, this article will explore how Chen's essay envisions what it means and what it feels like to be a mother of Chinese origin in contemporary Canada. In the process, this article will also contribute to a wider understanding of the condition of migrant mothering and touch upon critical debates around literatures of mobility. ${ }^{1}$
\end{abstract}

Keywords: motherhood; migration; $21^{\text {st }}$ century women's writing

Since the 1990s, Western literatures have seen an unprecedented number of femaleauthored texts that explore motherhood and mothering. Two studies published in 2009 identify and analyse this important trend. In her book Narratives of Mothering on contemporary French women's writing, Gill Rye analyses 'mothers' own narratives of mothering', which she defines as 'literary texts where the mother is herself either the first person narrative subject or, in third-person narratives, the figure whose point of view is paramount'. (Rye 2009: 15-17) ${ }^{2}$ In an edited volume From the Personal to the Political: Toward a New Theory of Maternal Narrative, which was published the same year and which focuses on North American women's writing, Andrea O'Reilly coins

\footnotetext{
${ }^{1}$ I am grateful to the editors of this special issue for their insightful and constructive comments to drafts of this article.

${ }^{2}$ Before then mothers were mostly represented through the eyes and discourses of others: 'sons, daughters, husbands, lovers'. (Rye 2009: 13)
} 
the term 'matrifocal narrative', defining this as a narrative in which 'a mother plays a role of cultural and social significance, and in which motherhood is thematically elaborated and valued, and structurally central to the plot'. (Podnieks and O'Reilly 2010: 3) Together, these observations signal an important cultural shift, namely a growing interest in motherhood as experienced, represented and conceptualised by mothers themselves. In this sense, Rye's notion of 'narratives of mothering' is particularly useful, as it makes it possible to identify and analyse mothers' voices and subjective reflections on mothering experiences. ${ }^{3}$ Some of the matrifocal literary narratives written from the mother's perspective in different languages and belonging to different national and cultural traditions (often more than one) take the experience of migrant mothering as their thematic and structural focus. ${ }^{4}$ Following Rye's terminology, these can be called narratives of migrant mothering and defined as literary texts written from the migrant, exiled, refugee or expatriate mother's perspective and in which motherhood is thematically elaborated.

This article focuses on two narratives of migrant mothering, namely Ying Chen's essays La lenteur des montagnes (The Slowness of the Mountains) (2014) and, to a lesser degree, 'Lettre d'Umbertide' (Letter from Umbertide) (2004), written in the form of letters to Chen's two sons, Lee and Yann. The aim of the article is to question what it means to be a mother of Chinese origin in contemporary Canada and, in a broader sense, what it takes to mother across several cultures and languages. As Sarah

\footnotetext{
${ }^{3}$ Rye chooses the word mothering over motherhood and maternity for 'its ability to privilege the multiple experiences of mothers.' (Rye 2009: 31-32) The distinction between motherhood as institution and motherhood as experience was made by Adrianne Rich in her 1976 classical text Of Woman Born. It is now common to refer to 'motherhood' as a socially, historically, culturally and ideologically constructed status or identity and 'mothering' as an individual practice not even dependent on gender. See for example Andrea O'Reilly's most recent book Matricentric Feminism: Theory, Activism, and Practice (O’Reilly 2016).

${ }^{4}$ Migrant here is used as a general term to designate people's movement from one country to another and implicitly includes all forms of migration such as refugeedom, economic migration, expatriation as well as political and voluntary exile.
} 
Ruddick famously observed, mothering mostly consists of protecting, nurturing and training (Ruddick 1989: 23), which, according to O'Reilly includes 'keeping [...] children safe and ensuring that they have a sense of belonging in their culture'. (O’Reilly 2014: 79) This article seeks to answer the thorny question of how a migrant mother ensures her children's sense of belonging in a culture and language to which she does not fully belong herself.

The article is divided into two parts. The first part discusses migrant mothering practices, as they are represented in Chen's letters to her children. The second part is concerned with migrant maternal subjectivity, in which the language of mothering plays an important role. I begin by situating Chen's work in the critical context of literatures of mobility, briefly considering two strands of its critical reception, namely its treatment as écriture migrante (migrant writing) (Chartier 2002) and as representing "Braidotti's nomadic vision of existence" (Rodgers 2015:51). A theoretical framework centring on 'talk story,' a culturally specific Chinese migrant mothering practice is then outlined. These serve as the analytical tools for discussing the advice Chen offers her mixed-race children. I then utilize Chen's metaphor of two trains to discuss her identity formation in more depth. I conclude with a consideration of the link between Chen's language of mothering as detailed in the essays at hand and her creative aesthetic practices as a migrant author.

\section{Ying Chen's Oeuvre Between Migration and Nomadism}

Ying Chen was born in 1961 in China and grew up in the former French concession in Shanghai. ${ }^{5}$ Having completed her studies in Modern Languages at Fudan University,

\footnotetext{
${ }^{5}$ The French Concession is the area of Shanghai once designated for the French, consisting of today's Luwan and Xuhui Districts.
} 
she worked as a translator and interpreter at the Institute of Astronautical Research in Shanghai (1983-89), using Mandarin, Italian, English and French. Chen emigrated to Canada in 1989, at the age of 28 , in what Gabrielle Parker calls 'a self-imposed exile from her parents, family, culture and language'. (Parker 2016a) Chen completed an MA in French and creative writing at McGill University and later lived in Magog (Quebec) before moving to Vancouver in 2003 to be closer to her husband's job. Now she is a widowed mother of two grown up children. Chen writes in French and is generally considered to be a Quebecoise author. However, she has also published in France and China, as she has translated her own work into Chinese. Her books have also been translated into Italian, English and Spanish, which suggests that her work can equally be situated in the context of several national literary traditions. She has published eleven novels to date and has been conferred with numerous literary awards, including the Prix Québec-Paris. In 2002, Chen was made Chevalière des Arts et Lettres.

The first three of Chen's novels, published between 1992 and 1995, are set in China. This is possibly one of the reasons why the early critical reception in Quebec classes her oeuvre as écriture migrante. This term came to denote literature produced in Quebec by a group of writers 'having a foreign geographical birthplace and/or mother tongue and for whom the personal experience of having left behind the original homeland is a common preoccupation of their literary output'. (Rodgers 2015: 53) As this quotation suggests, écriture migrante abides by the binary logic of there and here, then and now. Though there is no denying that China is a significant physical and cultural location in Chen's life and work-her first three novels as well as the latest novel Blessures, published in 2016, are set there - the poetics of Chen's work resist the binary logic inherent to the notion of écriture migrante.

Contesting the label of a 'migrant author', Chen, in her 1998-2013 novel series, 
makes a conscious and methodical effort to avoid geographical and cultural references (Parker 2016a; LU 2004). ${ }^{6}$ This produced numerous responses based on theoretical frameworks that allow for more nuanced articulations of the migratory sensibility in Chen's work (Dupuis 2011; Silvester 2007, 2011; Parker 2011; Rodgers 2011; 2015). Most notably Julie Rodgers (2015) reads identity in Chen's novels through Rosi Braidotti's theory of nomadic subjectivity; specifically, she suggests that identity in Chen's work is represented as not fixed, but fluid and constantly evolving. Nevertheless, Rodgers notes that despite its otherwise clear articulation of a nomadic consciousness, Chen's work displays some 'recourse to binary logic'. (2015: 66) Nomadic consciousness signifies a theoretical thought that conceives the world and the subject that inhabits it 'beyond the dualistic conceptual constraints'. (Braidotti 2011: 22) This article argues that within Chen's work, in particular in her descriptions of the evolution of her identity as a migrant mother, both migratory paradigms - the binary and the nomadic - temporarily coincide. Outside of Rodger's study, the problem of motherhood in Chen's work has not been thoroughly addressed. This article will attempt a more in-depth exploration of how migrant mothering is represented in Chen's non-fictional texts La lenteur des montagnes and 'Lettre d'Umbertide'.

\section{Talk Story}

The framework for this analysis utilises theories of literatures of mobility such as 1 . the concept of écriture migrante, and 2. Rosi Braidotti's theory of nomadic consciousness outlined above and 3. the notion of the talk story, developed by research in contemporary women's writing in the Asian diaspora.

\footnotetext{
${ }^{6}$ Chen's text entitled 'Lettre d'Umbertide' written to her elder son Yann and included in the collection of essays Quatre mille marches, un rêve chinois (Four Thousand Steps, a Chinese Dream) (2004) anticipated the themes and structure of La lenteur des montagnes (2014) and will be referred to in the article as LU.
} 
The term 'talk story' was first used by Maxine Hong Kingston in her famous memoir The Woman Warrior: Memoirs of a Girlhood Among Ghosts. Kingston writes: 'My mother told stories that ran like this one, a story to grow up on. She tested our strength to establish realities. Those in the emigrant generations who could not reassert brute survival died young and far from home'. (Kingston, 1977: 6) Talk story consists of episodes from family history or folklore that are designed to provide moral and practical guidance to young people. It also offers survival strategies drawn from timetested collective knowledge that opens up inner spaces of cultural and personal identity negotiations to which first and second-generation immigrants are inevitably subjected. Talk story has been theorised as the most popular paradigm of the mother-daughter relationship, as well as a mothering practice characteristic of Asian American mothering.

According to Anne Marie Lee-Loy: 'Embedded in such stories are the skills and knowledge that mothers believe their daughters will need to survive and contest North American discourses and practices of domination'. (2010: 318) In short, talk story provides daughters and, I suggest, sons too, with: 1. complicated and hardly definable truths about the world they live in; 2. unwritten and possibly controversial social norms that might be unfavourable to them; 3. examples of potential and potentially difficult situations they might find themselves in; and 4. behaviours they might want to adopt in those situations. The personal, communal and national histories in this context serve, for ethnic minority children, as points of identification needed for constructing themselves, both as individuals and in terms of community belonging, including, importantly, racial community belonging.

Talk story as a mothering practice has additionally been conceptualised as a means to give children access to the maternal and bilingual heritage, as well as the 
literary traditions in which their mothers were raised. Finally, and most importantly, as King-Kok Cheung (1999) has pointed out, the talk story is instrumental in nurturing children of migrant mothers's ability to see truth as multidimentional, as something which acknowledges different ways of composing the self.

The theory of the talk story as a mothering practice has been developed in relation to Anglophone Asian American women's writing. According to Cheung, this is partly shaped by 'parallel experiences' of North American writers of Asian descent in the United States and Canada after the Second World War (Cheung 1999: xv). Chen's work technically does not belong to the Anglophone Asian American literary tradition-her novels are written in French and long after the Second World War. Moreover, Chen left China for Canada not, like other Anglophone Asian American writers, in search of work, but on a quest for identity, driven by her ambition to become a writer (LM: 77). Notwithstanding these differences, the fact that she is a Chineseborn author living and working in Canada makes the use of talk story as a tool for analysing her work justifiable and productive. Applied to La lenteur des montagnes and 'Lettre d'Umbertide', talk story becomes not only a culturally specific Chinese mothering practice, but an act of mothering in migration.

\section{Talk Story in Chen's La lenteur des montagnes}

The essay La lenteur des montagnes is a long letter to Chen's younger son, Lee. ${ }^{7}$ It is written to him when he is about seventeen - in Chen's words, at the moment when he is 'leaving childhood and is approaching the adult world'. (LM 2014: 10) This suggests a certain rite of passage for him, but also for Chen as a mother. It is her attempt

\footnotetext{
${ }^{7}$ Although the book is dedicated to both her sons: 'To Lee, and also to Yann, who knows how to read what is neither said nor written.' Here and throughout the article translations from French are mine. Subsequent references to La lenteur des montagnes (LM) will be given in the text.
} 
to provide him with some guidance for the future: 'Now that a thousand activities are calling you and, I hope, will ensure your development, I can no longer clutch you in my arms in silence'. (LM, 26-7) This appears as a symbolic act, initiating her son into some of the ways of the adult world — the world of social norms and langue(s) — through talk story.

The first two fundamental pieces of knowledge Chen chooses to communicate to her son originate in her migrant status. These are a source of suffering, both for him and for her on his behalf. Firstly, although Canada is Lee's birth country, Chen says he does not enjoy the same rights of belonging there as Chen does in China because even at a young age Lee has to deal with racism, with 'the deaf reality of being Canadian without being white.' (LM: 36) He is confronted with the different symbolic status of the languages he has been brought up with-French, English and Chinese. ${ }^{8}$ All of this adds up to the 'almost primeval suffering', which Chen attempts to soothe through talk story. In Chen's case, as a multilingual writer mother, this is no longer a 'casual everyday storytelling particularly concerned with the sharing of life stories', (Lee-Loy 2010: 330) but a sophisticated, carefully and beautifully crafted book-length essay. ${ }^{9}$

The suffering is caused by what Lee-Loy terms 'North American discourses of domination' that reduce both Chen, her son, and all other people of Chinese origin in Canada, to their collective cultural and racial identity. Chen writes to Lee:

I can only confide to you how I try to find serenity in the life where my birth is turned into something predominant, where every one of my actions is interpreted from the angle of a "culture", or even "race", where all my books

\footnotetext{
${ }^{8}$ Chen's children were born in Quebec and brought up bilingual, French-Chinese. From 'Lettre d'Umbertide' we learn that her elder son started learning English at school. We can assume the same for her younger son Lee.

${ }^{9}$ All the texts in La lanteur des montagnes had been previously published in one-way or another (Parker 2016b).
} 
are often interpreted as essentially "Chinese", where my individuality is denied. (LM: 13)

The discourses she describes ignore the underlying reasons for her departure from China and her intimate, unique, highly complex and personal path. Additionally, Chen instructs Lee in how to withstand and resist such discourses and their effects — or, in Lee-Loy's words, to contest them.

Chen's first piece of advice to her son is simple and down to earth: 'There is therefore no reason to let yourself be influenced by the gaze of others, to give power to those who impose their law by their gaze'. (LM: 44, emphasis in original) This is a clear maternal warning that there will be relentless attempts to take the power of selfdefinition away from her son and that he will have to be vigilant and careful not to relinquish this, to always be conscious of the mechanisms of his own identity construction. This warning further suggests that it is up to him to divert the limited and limiting 'gaze of others' and simultaneously expand that ready-made framework for his identity.

The second piece of advice Chen offers her son is far more complicated, and this time of a philosophical and existential nature, rather than a practical one. It is intended, as Parker observes, 'to impress upon her son the relativity of difference'. (2016: 169) One of the functions of talk story is to pass on the knowledge that there are different, culturally specific ways of constructing a self, one's self. With this in mind, Chen tells her son in a subtle, metaphoric and sophisticated way how she came to nurture herself into the person, writer and mother that she is. In so doing, she offers him tools to construct his own identity, which she knows will never be singular or unproblematic. These tools helped Chen to soothe the pain inflicted by her being forced to choose between Chinese culture and language and Western culture and language. 
This choice was imposed upon her by the 'gaze of others', one entailing a harsh binary logic which divides individuals into racialised and non-racialised categories of identity. The danger posed by such binary categories lies in their power to reduce certain individuals to identities based exclusively on their race, ignoring other aspects of their identity and denying them the power of self-definition.

The self that Chen thus constructs for herself is non-binary, non-fixed, multilingual, multicultural and complex, yet coherent. She gradually reveals the structure of her own identity in the letter to her son Lee. First, she takes him through the readings that shaped her worldview, starting with what she read when she was his age and ending with what she reads now. She then shares with him her experience of learning French, his first language, and finally explains to him the philosophical views that have framed her existence and identity. The principles of identity formation displayed in all the three stages described by Chen are indicative of nomadic subjectivity, as defined by Braidotti. ${ }^{10}$

\section{Nomadic Subjectivity}

According to Braidotti, 'the nomadic consciousness combines coherence with mobility'. (2011: 64) In other words, nomadic subjects collect identity features from different stages of their mobile lives, fitting seemingly disparate elements into a consistent whole. Following Braidotti's logic, Rodgers suggests that Chen's nomadic consciousness is 'perhaps most effectively evoked in Chen's description of her personal library' (2015: 66), in which books in French, Chinese and English are arranged alphabetically according to names of their authors, rather than by language, genre, or

\footnotetext{
${ }^{10}$ Rodgers (2015) explores nomadic sensibility in Chen's work that precedes La lanteur des montagnes.
} 
the time or place of their production. Rodgers equates Chen's principle for organising her collection of books into a coherent whole with Braidotti's nomadic consciousness, which organises the multiple elements of migrant life into an articulate self (Rodgers 2015). The same can be said about the formative corpus of the texts that Chen cites to her son, which features writers as disparate as Confucius, Laozi, Valérie, Rilke, Beckett, Sarraute and Woolf. This corpus suggests a highly eclectic, substantial world literary tradition with the strong element of classical Chinese literature Chen was raised with and which she now seeks to pass on to her son.

In her literary act of mothering, consisting of the two letters to her respective sons, Chen uses the traditional Chinese practice of talk story. This suggests that as a parent, she is deeply, emotionally, and possibly unconsciously, invested in Chinese culture and in Chinese ways of bringing up children. However, when it comes to the content of her mothering, rooted in her own intellectualised experience of migration, she transcends the boundaries of her national identity to embrace the complex process of nomadic subjectivity construction described by Braidotti.

\section{The Metaphor of Two Trains}

Toward the end of the essay, Chen tells her son about how she first started learning French at university. At the age of eighteen this was not easy, especially because it was a language 'so different from Chinese'. (LM: 81) In an effort to describe why she considered French so completely alien to her worldview and thus so difficult to learn, Chen developed an extended metaphor of two trains. This metaphor conforms to a binary logic, as is evident in the following quotation: 'China and the West seemed to me like two trains departing from different destinations, going at incomparable speeds, following divergent routes, but, nevertheless, transporting a crowd fed on similar 
aspirations'. (LM: 81) The trains in Chen's metaphor, in that they depart from 'different destinations', stand for two rather broad and abstract geographical and cultural locations, China and the West - locations whose historical references are starkly dissimilar. The trains departing from each location proceed 'at incomparable speeds' and follow 'divergent routes'. Their only similarity stems from the passengers riding the trains, as they are united by 'similar aspirations' that are never explained, but presumably entail the bid to reach the destination.

Trains run on fixed tracks. In this metaphor, each rail track stands for a language and the worldview inherent in that language. Chen's equating of languages, and the respective worldviews they represent, with train tracks, presents these languages and worldviews as inflexible regulatory frameworks. As speakers of the languages represented by the rail tracks, the passengers - specifically, their mentalities and their identities - are shaped by these inflexible regulatory frameworks.

Adding to this image of fixedness and inflexibility, train passengers - as distinct from pedestrians - are images that evoke something passive and still. Train passengers choose their itineraries, but not the exact travel routes or the speed at which they travel. They are carried along previously designed, pre-set train tracks, without much control over the course of their journey. This includes the scenery passengers see through the window. And these are the elements that constitute the passengers' reality. If trains and rail tracks stand for languages and passengers for language users, it is then possible to argue that train passengers, that is to say, people who have learnt only one language and in the country where that language is dominant, are overwhelmingly influenced by the worldview of that language. Their mentalities are largely shaped and also limited by those languages. This suggests that people who speak only one language, who live 
in and see the world through the lens of one linguistic and cultural paradigm, are at least partly oblivious to different ways of experiencing the world.

When Chen first started learning French, she struggled with the difference between French and Chinese and the respective worldviews associated with each language. However, she sensed that when she mastered French, that she simultaneously acquired an ability to perceive the world the way a French speaker and a Westerner might. Chen observes:

I thought that if the trains could stop for a moment, if the passengers could all get off and swap places before continuing their journey, which would henceforth change in nature, since they would have stepped into the shoes of others, into the condition of others and even into the past and future of others, they would speak of others, who would not be others any more, more attentively and possibly even with a touch of solidarity. (LM: 81-2)

Thus Chen suggests that having one language speakers exchange places with speakers of another language, then having each set of language users see the world shaped by a different linguistic and cultural paradigm would mean that each set of language users would view the world from a perspective that is different from the one from which they had previously seen it from.

Getting out of one train - that is to say, liberating oneself from one culturally specific mental framework - can open one up to cultural and linguistic differences. However, the first step necessary for achieving such a liberated state of mind, according to Chen, involves crossing over from one linguistic and cultural paradigm to the other. This means learning to speak the language of the new country and to navigate its cultural landscape, in other words, integrating oneself into the new country. Integration into a new culture without losing or relinquishing one's native language, identity and 
worldview results in a liminal existence between two cultures, as one is constantly mentally travelling between the two linguistic and cultural paradigms. However, following Chen's reasoning, behind the metaphor of the two trains, such an existence implies lack of individuality. It suggests that people who migrate from one cultural paradigm to another in a linear manner remain defined by the linguistic and cultural models of those particular cultures. This mode of existence is binary in nature and belongs to the migratory logic characteristic of écriture migrante described above. By the time Chen writes the long letter to Lee discussed in this article, she has already distanced herself from the binary migratory pattern of living between two cultures and languages, between two trains and their different speeds. At the time of writing $\mathrm{La}$ lenteur des montagnes, she says she had decided to travel on foot, at her own speed, taking paths of her own choosing.

Now, far from all trains, I have to walk [...] believing that speed is not everything and hoping to see on the way, doesn't matter whether it is China or the West, what you cannot see whilst comfortably settled on board of one train or one shuttle. (LM: 83)

In this quotation, Chen tells us that she has opted out of selecting either of the two trains, choosing instead to travel on her own feet, at her own speed, attending to the elements of the scenery that go unnoticed by the passengers on both trains. Walking, as opposed to riding on board a train in this way, presents a strong image of selfhood and agency. It seems to me that she who walks on her own feet is grounded, self-confident and able. She is strong and independent, capable of self-definition. She who chooses to live, write and mother across languages cannot afford to be carried along the train tracks of a single language, a single culture and a single mentality. She needs to be able to meaningfully engage with at least two cultural paradigms. Furthermore, she must also 
be able to withstand and resist them both. She must create her own track in order to be able to nurture her children who, by being born in a mixed family, defy the binary logic of Chinese culture and language vs Western culture and language.

Chen's decision to literally trust her own feet rather than either of the two trains and their tracks marks a crucial identity shift in Chen's life and work. It represents a decision to refuse the painful gaze of the other, one that is consistently reduced to one linguistic, cultural and mental paradigm, one which fails to acknowledge the multilingual, multicultural migrant reality in which Chen lives. To travel on one's feet signifies enjoying a sense of self-possession. If Chen passes through different cultural sensibilities on her own feet, that is to say, in a self-conscious and self-sustaining way, then she stands a chance of surviving. Moreover, passing through on one's own feet allows her to take time to 'reflect on the scenery' and to make the vital 'situated connections' that feed into the coherent sense of what Braidotti terms 'nomadic consciousness'. Braidoti explains:

Nomadic consciousness consists in not taking any kind of identity as permanent: the nomad is only passing through; he makes those necessarily situated connections that can help him to survive, but he never takes on fully the limits of one national identity. (2011: 64)

Chen's choice to select neither the train departing from China nor the train departing from the West constitutes a refusal to alternate between the two separate identity paradigms, each comprised by a distinctive culture, language and nation. This move implies the embracing of the sort of 'nomadic consciousness' Braidotti describes, as Chen's means for the construction of her migrant identity. 


\section{Yi Jing and the Law of Change}

The main literary reference Chen utilizes to situate her personal nomadic philosophy, is the oldest and most iconic of the five Chinese classical texts, Yi Jing (Book of Changes). It is a text of philosophy and divination and is often used to provide guidance for moral decision making as informed by Taoism and Confucianism. The text is only available to Chen in translation, in Western languages, as it was originally written in ancient Chinese. Despite there being several translations of Yi Jing, in various Western languages, Chen claims to trust only one: Richard Wilhelm's translation from ancient Chinese to German, which Wilhem subsequently translated back into ancient Chinese (in order to check the meaning with his Chinese teacher). As Parker astutely observed: 'In order to be able to translate the Yi Jing text, Wilhelm was willing to translate himself into a different thought system, alter his own Weltanschauung, so as to bring back this perspective to Western readers'. (2016b)

This project of double translation resonates with Chen's own journey toward identity as follows: Both reflect a belief that someone who has consciously left one cultural mind-set and entered another can only be sure of the viability of her transformation if she goes back to her culture of origin to register the differences between her initial identity (and its associated cultural mind-set), and her 'new' identity (and its cultural mind-set). Chen's essay suggests that the identity transformation she initially experienced involved a binary change in which she passed from Chinese to Quebecois in language, culture, identity and worldview. As a result, she lost the ability to switch between the two languages, cultures and identities and worldviews at will. She confesses: 'It has taken me years, with my slowness to cross the Pacific and the Atlantic Oceans, with the help of translations at first and then learning the languages' 
(ML: 79) This is to say that Chen perceives her crossing from Chinese to being Quebecois as complete and irreversible at the time she wrote this.

Nevertheless, the main message of Yi Jing, as interpreted by Chen, centres on the importance and relentlessness of the principle of transformation. 'Change', she writes 'is the absolute law in the world without the absolute'. (LM: 12) If identities, including linguistic identities, are also subject to the law of change and, if, as Chen puts it, 'civilisations, just like languages are not made to last forever', (LM: 12) then she, as a mother, must concede that her children will not perpetuate her linguistic and cultural identity, one that is anchored in Chinese language and culture. Thus, after having travelled from one language and culture to another, after becoming a mother, and, in particular, having her children grow up and develop their own multicultural and multilingual identities, Chen is forced to push herself one step further. She must fully embrace the law of change, expanding it beyond the simple, binary logic of China vs the West.

In 'Lettre d'Umbertide', Chen writes: 'this ineffable maternity has triggered in me a need to change perspective'. (LU: 85) She goes on to explain how the change of perspective is reflected in her work. She dates this change to the year 1998 and the publication of her book L'Immobile, which was written around the same time that she gave birth to her two sons in quick succession. With this novel, she turns away from her previous geographical and cultural references and begins developing 'the aesthetics and an approach specific to me', (LU: 87) that is, the very aesthetics and approach that Braidotti calls nomadic. 


\section{The Language of Mothering}

La lanteur des montagnes, Chen remarks that 'in the experience of migration, the 'linguistic difference is one of the most significant differences'. (LM: 85) In terms of her own maternal linguistic subjectivity, Chen observes, that the birth of her children has set in motion a process of identity change that is filled with conflict. On the one hand, it inspired the desire to 'go back to source [...] this sharp consciousness of my own coming into the world'. (LM: 42) On the other hand, Chen sensed 'the need to change perspective', (LU: 85 ) to turn away from a binary migratory logic to a more fluid, nomadic one.

Chen's need to figuratively return to her origins is more complex than it might initially appear. She admits to having 'mentally departed' from China before she even left the country. Nevertheless, in letters to both her children she writes extensively about her efforts to teach them Chinese, their mother's language. ${ }^{11}$ She talks about numerous private lessons she had arranged for them both and about the Chinese TV series that she does not enjoy but watches with her sons for language teaching purposes. She refers to her relentless efforts to ensure her children's proficiency in Chinese as a 'daily battle' that is doomed since 'languages are not made to last'. (LM: 72)

Thus, Chen's return to her Chinese origins and language, her attempt to pass these on to her children and her recognition of the limited success of this enterprise, turns into a painful experience for her. Despite her intellectual disengagement from China years before, it is clear that emotionally, Chen still feels very much attached to

\footnotetext{
${ }^{11}$ Chen refers to Chinese in relation to her children as their 'langue maternelle', that is to say, their mother tongue. However, since according to some perspectives, their mother tongue is French, I call Chinese their mother's native language here.
} 
China and suffers from this in the face of her children's inability to identify with her native country and language. ${ }^{12}$ Chen describes this as follows:

This process of deculturation happens every day in front of my eyes. When I was leaving Shanghai and when you were born, I had predicted it, I had understood, but I did not know that it would cause me so much suffering. ( LM:

The involuntary, uncontrollable and unconscious nature of her emotional response, coupled with the pain it causes Chen - despite her previous mental preparations for the eventuality that her children would not speak Chinese very well and would not identify as Chinese - demonstrates how authentic and profound the link between the mother's native language, cultural identity and the language of mothering can be. Chen clearly feels a powerful and inexplicable need to pass on her linguistic and cultural identity to her children, despite the fact that intellectually and personally, she had moved on from this identity herself.

For Chen's Canadian-born and raised children, who speak Chinese and French at home and are learning English at school, their mother's native Chinese is not the language in which they are most fluent. Their mother's tongue remains foreign to them. Their linguistic and cultural identity is manifold and complex, feeding on multiple sources from day one, as the boys are, according to Chen 'projected into this wandering' (LM: 54) that they had not chosen, but rather a wandering that Chen had begun on her own. They are nomadic by birth. Thus, in order to develop a common identity with her sons, in order to remain recognisable to them, Chen feels the need to reinforce the already existent, nomadic aspect of her own self. To put it in Braidotti’s terms, Chen is

\footnotetext{
${ }^{12}$ In her response to this essay, Parker makes the same point: 'Only two things bind her [Chen] to the place where she was born, her parents and language, emotional ties in both cases.' (2016b)
} 
shown to transform her permanent national identity, her emotional identification with China into one of the linguistically and culturally situated sources, a small but powerful connection that helps the nomad to survive.

\section{Conclusion}

In conclusion, Chen's essays La lenteur des montagnes and 'Lettre d'Umbertide' offer a twofold answer to the question of how a migrant mother ensures her children's sense of belonging in a country to which she does not fully belong herself. First, in the longstanding Chinese diaspora tradition of talk story, she warns about the prejudice they will have to face as racialised second-generation immigrants into contemporary Canada. She cautions them against being limited to an inadequate identity should they concede the power of self-definition to the outside gaze and encourages them to develop a strong sense of self based on multiple cultural and linguistic influences individualised into an original identity. She thus gently instructs them to let go of the idea of straightforward belonging to the imaginary homogeneous country and culture. Instead, she urges them to embrace a multidimensional idea of being.

Second, she shares with her sons her own experience of living, writing and raising them between several cultures and languages. For Chen, the most important aspect of her mothering in migration turns out to be ensuring her own lasting relationship with her children, which provides them with a form of belonging. That relationship depends on drawing on the multiple linguistic, cultural, and intellectual influences individually shaped into coherent identities and can thus be considered to be instrumental in building the children's sense of belonging to their country of birth and residence as it structures and emotionally supports multiple and culturally complex identity that requires constant negotiations. Transmitting Chen's native language to her 
children proves to be the central element of that lasting relationship and identity construction for both her as a migrant mother and her children. Furthermore, the link between Chen's evolving migrant maternal identity and changing creative aesthetic practices that as a result of her becoming a mother moves away from the culturally specific binary logic towards more encompassing nomadic consciousness provides evidence of the mothers' subjectivity developing together with her children's identities and siding along with them. This link also points out to the significance of the association between maternal and migrant identities that calls for further investigation.

Acknowledgements: This work was supported by the Lithuanian Research Council [grant number VP1-3.1-ŠMM-01-V-02-004]

\section{Works Cited}

Braidotti, Rosi (2011), Nomadic Subjects, New York: Columbia University Press.

Chartier, Daniel (2002), 'Les origines de l'écriture migrante. L’immigration littéraire au Québec au cours des deux derniers siècles.' Voix et Images 27.2, pp. 303316.

Chen, Ying (2004), 'Lettre d'Umbertide', in Ying Chen, Quatre mille marches. Un rêve chinois, Paris: Seuil, pp. 83-90.

— (2014), La lenteur des montagnes, Montreal: Boréal.

Cheung, King-Kok (1993), Articulate Silences, Ithaca and London: Cornell University Dupuis, Gilles (2011), 'La littérature migrante est-elle universelle? Le cas de Ying Chen', Croisements 1, pp. 23-33.

Kingston, Maxine Hong (1977), The Woman Warrior, New York: Vintage. 
Lee-Loy, Anne-Marie (2010), 'Asian American Mothering in the Absence of Talk Story: Obasan and Chorus of Mushrooms', in Elizabeth Podnieks and Andrea O'Reilly (eds), Maternal Texts. Motherhood in Contemporary Women's Literatures, Waterloo: Wilfrid Laurier University Press, pp. 318-329.

O'Reilly, Andrea (2014), Mothering and Motherhood Across Cultural Differences, Bradford, ON: Demeter Press.

- (2016).Matricentric Feminism: Theory, Activism, and Practice, Bradford, ON: Demeter Press.

Podnieks, Elizabeth, O'Reilly, Andrea (eds.) (2010), Textual mothers / Maternal Texts: Motherhood in Contemporary Women's Literatures, Waterloo, Ont.: Wilfrid Laurier University Press.

Parker, Gabrielle (2011), 'A mi-chemin entre deux mondes: parcours féminins chez Ying Chen', Relief 5.2 http://www.revue-relief.org/index.php/ $\underline{\text { relief/article/view/690/757 }}$

— (2016a), 'Ying Chen. Biography', available on the Institute of Modern Languages Research website at http://modernlanguages.sas.ac.uk/centre-studycontemporary-womens-writing-ccww/languages/french/ying-chen （viewed September 2016).

— (2016b), 'Ying Chen's Critical Path: the Writer's Search for a New Perspective', Nottingham French Studies 55.2, pp. 158-173.

Rich, Adrianne (1986), Of Woman Born, New York-London: W.W. Norton \& Company.

Rodgers, Julie (2011), 'La dualité de l'être chez Ying Chen', Dialogues francophones 17, pp. 81-91.

— (2009), 'Comment peut-on être moi quand on est Mère ? Une étude de la maternité 
dans Un enfant à ma porte de Ying Chen', International Journal of Canadian Studies 45-46, pp. 403-416.

— (2015), “On s'occupe du multiple, on tourne le dos à l'unité”: Ying Chen and Nomadic Figurations of the Subject, Québec Studies, 59, pp. 51-69.

Ruddick, Sara (1995), Maternal Thinking: Toward a Politics of Peace, Boston: Beakon Press.

Rye, Gill (2009), Narratives of Mothering. Women's Writing in Contemporary France, Newark: University of Delaware Press.

Silvester, Rosalind (2007), 'Le récit de vie(s): immobility and fluidity in Ying Chen’s works', Forum for Modern Language Studies 43.1, pp. 57-68.

— (2011), 'Ying Chen and the Non-Lieu', Modern Language Review106, pp. 407-22. 